\title{
Rho GTPases in human carcinogenesis: a tale of excess
}

\author{
Salvador Aznar. Benitah, Carolina Espina, Pilar F. Valerón and Juan Carlos Lacal \\ Instituto de Investigaciones Biomédicas. CSIC. Madrid.
}

\begin{abstract}
Rho GTPases are proteins that in response to diverse stimuli control key signaling and structural aspects of the cell. Although early studies had proposed a role for Rho GTPases in cellular transformation, this effect was underestimated by the fact that no genetic mutations affecting Rho-encoding genes was found in human tumors. However, in recent years a high incidence of overexpression of different members of the family of Rho GTPases in human tumors has been detected which is leading to a great interest in the cellular effects elicited by these oncoproteins. As well, the characterization of downstream effectors and upstream regulators of Rho GTPases provides crucial clues on the specific cellular effects that permit aberrant cellular growth and tumorigenesis. A direct link between the functions of some of these signaling elements and regulation of the cell cycle, cytoskeletal rearrangements and cell adhesion has been observed in distinct types of human tumors. Provided this information, a number of drugs that affect Rho signaling at different levels have been described with promising in vivo antitumoral activity. In this review, the current evidence of dysregulation of Rho signaling in human tumors is assembled.
\end{abstract}

Key words: Rho GTPases, human tumors, protein overexpression, antineoplastic targets.

Aznar Benitah S, Espina C, Valerón PF, Lacal JC. Rho GTPases in humam carcinogenesis: a tale of excess. Rev Oncol $2003 ; 5(2): 70-8$

\section{GTPasas Rho en carcinogénesis humana: una cuestión de exceso}

Las GTPasas Rho regulan un alto número de procesos de señalización y estructurales de la célula en respuesta a diversos estímulos. El hecho de que no se haya detectado mutación alguna en la secuencia primaria de ningún miembro de la familia de GTPasas Rho ha conllevado a que se subestimase su posible papel en la biología de diversos tumores humanos. Sin embargo, el creciente número de trabajos recientes que describen una elevada incidencia muy alta de sobreexpresión de las proteínas Rho en un alto número de tumores ha suscitado mucho interés en la comunidad científica. La caracterización de proteínas efectoras y de la señalización dependiente de Rho ha permitido identificar los mecanismos a través de los cuales esta familia de proteínas inducen una proliferación aberrante $y$, en última instancia, el desarrollo y progresión del tumor. La relación entre la actividad de alguna de las proteínas efectoras de Rho con el ciclo celular, reorganización del citoesqueleto y la adhesión celular ha sido observada en diversos tipos de tumores humanos. Además se ha sintetizado una serie de compuestos que afectan las rutas de señalización dependientes de Rho a varios niveles y que muestran una actividad antitumoral in vivo prometedora. En esta revisión realizamos un detallado resumen del conocimiento actual acerca de la desregulación de las proteínas Rho en tumores humanos.

Palabras clave: GTPasas Rho, tumores humanos, sobreexpresión de proteínas, dianas antitumorales.

\section{INTRODUCTION}

Rho GTPases mediate housekeeping aspects of cell biology including cell size, mitosis/meiosis, proliferation, apoptosis/survival, cell polarity, cell adhesion,

Correspondence: Dr. J. C. Lacal.

Instituto de Investigación Biomédicas.

CSIC.

Madrid.

E-mail: jclacal@iib.uam.es

Received 13 January 2003; Accepted 11 February 2003. and membrane trafficking1-8. Indeed, these proteins are essential for processes such as embryonic development, immune and inflammatory responses, tissue differentiation, wound healing, and tissue morphogenesis. This ability to act as general modulators of essential biological processes confers them with the capacity to play important roles in tumor biology and other human pathologies (for an excellent review on Rho signaling in disease see reference ${ }^{9}$ ).

Several members of the Rho family of GTPases have been cloned to date. These include RhoA, RhoB, 


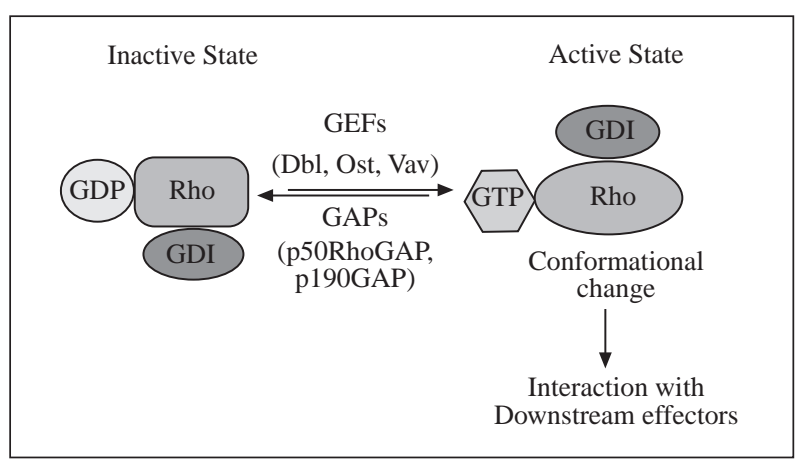

Fig. 1. Rho GTPases regulatory Cycle: GTP loading is catalyzed by Guanine Exchange Factors (GEF). Once bound to GTP Rho proteins undergo a complex conformational change that permits the interaction with downstream effector proteins. Inactivation occurs through the hydrolysis of GTP to GDP catalyzed by the synergistic effect of the intrinsic Rho GTPase activity with the enhancement of Rho GAPs (GTPase: Activating Proteins).

RhoC, RhoG, Cdc42, TC10, Rac1, Rac2, Rac3, Rho6/Rnd1, Rho7/Rnd2, Rho8/Rnd3, RhoE, RhoD, RhoH and Wrch ${ }^{1-2,10}$. These proteins catalyze the hy- drolysis of GTP to yield GDP, and binding to one form or another of the nucleotide is the basis of their regulated function. From a functional sense, Rho GTPases cycle between an active GTP-bound state, and an inactive GDP-bound state (fig. 1). This regulatory cycle is primarily controlled by three distinct families of proteins, guanine exchange factors (GEFs), GTPaseactivating proteins (GAPs), and guanine nucleotide dissociation inhibitors (GDIs). Upon GTP-loading, a conformational change takes place that allows Rho proteins to interact with several downstream effectors that ultimately process the information and propagate the signal within the cell (table 1). These effectors are subclassified as those with no intrinsic or with intrinsic enzymatic activity and might be specific to one or more Rho GTPases ${ }^{2}$.

Early studies demonstrated that murine fibroblasts that overexpressed constitutively active mutant RhoA, Rac1 or Cdc42 were tumorigenic in syngeneic mice ${ }^{11-13}$. Furthermore, Rho-transformed murine fibroblasts developed distant lung metastasis as determined with experimental metastasis studies ${ }^{13-16}$. In addition, besides constituting oncogenes on their own, Rho pro-

TABLE 1. Effectors for Rho proteins and their involvement in cell transformation, metastasis and apoptosis

\begin{tabular}{|c|c|c|c|c|}
\hline \multirow{2}{*}{ Effectors } & \multirow{2}{*}{ RhoGTPases } & \multicolumn{3}{|c|}{ Biological Effects } \\
\hline & & Proliferation & Metastasis & Apoptosis \\
\hline \multicolumn{5}{|l|}{ Rho } \\
\hline ROCK family & & + & + & + \\
\hline PKN family & Rac (PRK2) & + & & + \\
\hline Citron Kinase & & + & & \\
\hline \multicolumn{5}{|l|}{ Citron } \\
\hline \multicolumn{5}{|l|}{ Rhotekin } \\
\hline \multicolumn{5}{|l|}{ Rhophilin } \\
\hline $\mathrm{mDia1} / 2$ & & & & $?$ \\
\hline \multicolumn{5}{|l|}{ DAG $\theta$ Kinase } \\
\hline PLD & Rac/Cdc42 & + & + & \\
\hline \multicolumn{5}{|l|}{ PIP5Kinase } \\
\hline \multicolumn{5}{|l|}{ Rac/Cdc42 } \\
\hline WASP family & Cdc42/Rac1 & & + & \\
\hline IQGAP1/2 & Cdc42/Rac1 & & + & \\
\hline PAK family & Cdc42/Rac1 & + & + & + \\
\hline $\mathrm{ACK} 1 / 2$ & Cdc42 & + & + & \\
\hline $\mathrm{POSH}$ & & & & + \\
\hline POR1 & $\mathrm{Rac}$ & & & \\
\hline Borg family & Cdc42/TC10 & & & \\
\hline $\mathrm{MRCK} \alpha / \beta$ & Cdc42 & & & \\
\hline MLK-3 & Cdc42/Rac1 & + & + & \\
\hline MEKK-1/4 & Cdc42/Rac1 & + & + & \\
\hline $\mathrm{PI3K}$ & Rac/Cdc42(?) & + & + & \\
\hline p70s6kinase & & + & $?$ & \\
\hline p67PHOX & & & & + \\
\hline CIP4 & Cdc42 & + & & \\
\hline
\end{tabular}


TABLE 2. Dysregulation of Rho GTPases in different human tumors. (+) indicates overexpression of the indicated GTPase. Rac 2, Rac 3 indicates overexpression of this member of the family

\begin{tabular}{|c|c|c|c|c|}
\hline Type of tumor & RhoC & RhoA & Rac 1 & Cdc42 \\
\hline $\begin{array}{c}\text { Breast } \\
(\mathrm{BC} / \text { no-IBC) }\end{array}$ & + & + & $\stackrel{+}{\operatorname{Rac3}}$ & + \\
\hline Melanoma & + & + & & + \\
\hline Colon & & + & + & + \\
\hline $\begin{array}{l}\text { Head and } \\
\text { NeckSCC }\end{array}$ & & + & Rac2 & + \\
\hline $\begin{array}{l}\text { Testicular } \\
\text { (germiline) }\end{array}$ & - & + & & \\
\hline Ovarian & & + & & \\
\hline Pancreas & + & & & \\
\hline \multicolumn{5}{|l|}{ Neurobastoma } \\
\hline Osteosarcoma & & + & & \\
\hline Prostate & & + & & \\
\hline Lung & + & + & + & + \\
\hline Liver & & + & & \\
\hline Leukemias & & + & & \\
\hline
\end{tabular}

teins are necessary for cell transformation under several oncogenic stimuli. For instance, Ras and Rho GTPases-mediated transformation are not separate events, and the pathways controlled by both families of proteins form a complex signaling weave resulting in tumorigenesis ${ }^{17-24}$. In this sense, inhibition of RhoA, Rac1 or Cdc42, via ectopic expression of their dominant negative mutants, in Ras-transformed fibroblasts prevents cell proliferation, anchorage-independent growth and in vivo tumor formation ${ }^{20-22}$. The same holds true for tumors of epithelial nature in which Ras is the predominant oncogene ${ }^{17}$. Rho signaling is also necessary for aberrant growth promoted by several other oncogenic pathways including EGFR, IGFR, MET, RET and G-protein coupled receptors $^{24-30}$.

Much work has been done in the past decade to elucidate the mechanisms whereby aberrant signaling downstream of Rho GTPases leads to an efficient tumorigenic phenotype. As mentioned above, several effectors have been cloned and their functions characterized ${ }^{1-5}$. With respect to tumorigenesis ROCK, PAK, and IQGAP are among the best studied, and their contribution to Rho-mediated cell proliferation and invasion are fairly well studied (for extensive reviews on this topic see references 1-2, 6 and 9). In addition, several works suggest that regulation of transcription might be a key mechanism for Rhopromoted oncogenesis. Due to space limitations, in this review a summary of the incidence and implication of different Rho family members in human tumors will be made.
TABLE 3. Dysregulation of dowsntream effectors of Rho GTPases in different human tumors. PAKs are effectors to Rac 1 and Cdc42; ACK is a downstream effector to Cdc42; ROCK ser/thr kinases are effectors to Rho A and Rho C; IQGAP interact with Rac 1 and Cdc42; WASP and WAVE proteins are effectors to Cdc 42 and Rac 1 respectively

\begin{tabular}{|c|c|c|c|c|c|}
\hline Type of tumor & PAKs & ACK1 & ROCK & IQGAP & WASP \\
\hline $\begin{array}{c}\text { Breast } \\
(\mathrm{BC} / \mathrm{no}-\mathrm{BC})\end{array}$ & + & & + & & + \\
\hline Melanoma & + & + & & & \\
\hline Colon & + & & + & + & \\
\hline Testicular & & & + & & \\
\hline Ovarian & + & & & & \\
\hline Pancreas & + & & & & \\
\hline Osteosarcoma & & & + & & \\
\hline Neuroblastoma & & & & & WAVE \\
\hline Prostate & & & + & & \\
\hline Liver & & & + & & \\
\hline
\end{tabular}

\section{DYSREGULATION OF RHO GTPASES SIGNALING IN HUMAN TUMORS}

One determinant difference between Ras and Rho proteins with respect to human cancers is the lack of dominant point mutations that result in constitutive binding to GTP31-33. However, although no point mutations of Rho GTPases in human tumors have been found to date, overexpression of either the GTPase itself or mutation of some upstream or downstream element of Rho signaling has been detected in many human tumors. Thus, Rho signaling is modified in a large variety of human tumors as indicated in table 2 and table 3. The section below summarizes the incidence of Rho signaling dysregulation in human tumors with respect to different stages of tumor development.

\section{PANCREATIC TUMORS}

One of the first evidences of overexpression of a member of the Rho family of GTPases came with studies on pancreatic carcinogenesis ${ }^{34}$. In this study the expression of RhoA, RhoB and RhoC in 33 cases of ductal adenocarcinoma of the pancreas was studied through RT-PCR and protein level. Overexpression of RhoC, but not RhoA or RhoB, with respect to non-malignant tissue correlated with tumor grade, with higher expression in metastatic lesions when compared to primary tumours. In this sense, carcinoma tissue from lymph node metastases displayed very high levels of RhoC. Finally, RhoC was determined to be a marker of poor prognosis. As well, it was determined that overexpression of RhoC is an event independent of K-ras mutation.

Although overexpression of RhoA was not detected in any pancreatic tumoral tissue, nevertheless it might also be involved in pancreatic cancers. Two 3-hy- 
droxy 3-methylglutaryl coenzyme A (HMG-CoA) inhibitors, fluvastatin and lovastatin inhibit human pancreatic cancer cell invasion and metastasis ${ }^{35-36}$. This family of HMG-CoA inhibitors prevents the synthesis of cholesterol precursors, such as farnesyl pyrophosphate and geranylgeranyl pyrophosphate, necessary for proper membrane translocation of Ras and Rho proteins. Treatment with this family of inhibitors results in an efficient mislocalization of Ras and Rho proteins and their subsequent inhibition. In this sense, treatment of pancreatic cancer cell lines with both drugs results in efficient RhoA mislocalization and inhibition, leading to a reduction of the number of liver metastases produced by these cells when injected in mice. Furthermore, inhibition of EGF-induced cell invasion of pancreatic cells was achieved upon fluvastatin and lovastatin treatment, in a RhoAdependent manner ${ }^{35}$.

Although both RhoA and RhoC are involved in pancreatic cancers, several issues need to be addresses in future studies. For instance, no information about the pathways downstream of RhoC involved in the progression of pancreatic carcinomas is available. Furthermore whereas RhoC overexpression is independent on K-ras status, the same has not been tested with RhoA. Studies that establish a correlation, if any, between RhoC overexpression or K-ras mutation with RhoA activity in pancreatic cancers should provide useful information as to decide what better antitumoral treatment is to be used.

\section{BREAST TUMORS}

Increased expression of RhoC in other human tumors has been detected since then. Differential display of an inflammatory breast cancer (IBC)-derived cell lines with respect to primary cells was carried out and nine different transcripts were shown to be present in the tumoral cell lines and absent in the primary cells, of which one was found to be RhoC ${ }^{37}$. IBC is the most aggressive form of breast cancer that is highly infiltrative and metastatic with poor prognosis for the patients. Furthermore, this result was confirmed using in situ hybridization that indicated that approximately $90 \%$ of inflammatory breast tumors, and 38\% of noninflammatory breast tumors, overexpressed RhoC. The same group then investigated whether overexpression of RhoC was a pro-tumorigenic factor in IBC or a mere consequence of tumor genetic instability. Overexpression of wild type RhoC in primary human mammary epithelial cells enables the cells to grow on anchorage independent conditions ${ }^{38}$. Furthermore these cells were highly motile and tumorigenic when injected in athymic mice mimicking the tumoral phenotype of IBC-derived cell lines. It was found that these cells produce and secrete high levels of proangiogenic factors such as vascular endothelial growth factor (VEGF), basic fibroblast growth factor (bFGF), interleukin-6 (IL-6), and interleukin-8 (IL-8) when compared to normal untransformed parental cells ${ }^{39}$. Overexpression of RhoA, RhoB and RhoC, but not Rac1, correlates with tumor grade with high expression in grade III breast tumors compared to grade I. Surprisingly, all three RhoA, Rac1 and Cdc42 were overexpressed in 100\% of all tumoral breast tissues analyzed, and non-detectable in the normal tissue $\mathrm{e}^{40-41}$. This observation suggests that all three GTPases might be important for breast cancer progression, however it should be determined whether inhibition of each GTPase affects breast tumor growth.

Bouzahzah et al (2001) have recently elegantly shown that expression of dominant negative RhoA, Rac1 or Cdc42 in rat mammary adenocarcinoma cells affects tumor cell growth in vivo and reduce intravasation into the peripheral blood, thus inhibiting the formation of lung metastases 42 . Other studies have indirectly shown an important role of RhoA in breast carcinogenesis. For instance, treatment of highly metastatic breast cancer cell-lines with an inhibitor of 3-hydroxy 3-methylglutaryl coenzyme A reductase (HMG CoA reductase), termed cerivastatin, reduces the metastatic potential of these cells ${ }^{43}$. As already mentioned, HMG-CoA reductase inhibitors prevent RhoA and Ras membrane localization and activation. MDA-MB-231 cells treated with cerivastatin have impaired cell proliferation and invasion through matrigel. However, poorly metastatic breast cancer cells such as MCF-7 are less sensitive to cerivastatin, suggesting that RhoA might be more significantly overexpressed in late stages of breast cancer as with other tumors. The effects elicited by this inhibitor were determined to be due to RhoA-, but not Ras-mislocalization from the cell membrane since geranylgeranylation but not farnesylation counteracted the inhibitory effect of cerivastatin. Interestingly, treatment with cerivastatin resulted in RhoA-dependent inhibition of urokinase and MMP-9 expression further indicating that both these proteins are downstream targets of Rho involved in Rho-mediated tumorigenesis.

A number of other studies have pointed out a role of RhoA in human breast tumor progression and metastasis exerted by the CD44 hyaluronan receptor ${ }^{44,45}$. CD44 is expressed in human breast tumors and is a promoter of both cell growth and metastasis of tumoral cells. RhoA and CD44 directly interact in vivo in highly metastatic human breast cancer cell-lines resulting in RhoA activation. More importantly, inhibition of Rho signaling results in the abrogation of the metastatic phenotype elicited by CD44.

Dysregulation of another member of the Rho family of GTPases, Rac3, closely related to Rac1 has been detected in breast cancer ${ }^{46}$. Highly proliferative breast cancer cells MDA-MB 435, T47D, and MCF-7 but not 
normal breast cell lines or less proliferative breast cancer cells, contain constitutive active Rac3 signaling, in a Ras-independent manner. Interestingly, no dominant activating mutation is detected in Rac3 itself, suggesting that a regulatory protein might be impaired resulting in high constitutive Rac3 signaling. As also observed for RhoC, expression of a dominant negative mutant Rac3 (N17) leads to inhibition of Sphase entry and cellular proliferation indicating that Rac3 hyperactivation promotes cell growth.

The significance of dysregulation of Rho proteins is human breast cancer is starting to emerge. However, whilst it is now clear that overexpression of Rho GTPases takes place in different breast cancer derived cell lines and in tumoral tissues, the underlying mechanisms that follow Rho activation that result in the tumoral phenotype are mostly unknown. Some of the effectors to Rho GTPases involved in breast cancer have been recognized and will be discussed below. The specific pattern of Rho overexpression at different stages of tumor progression need to be further clarified. Furthermore, it should be determined whether Rho proteins are pivotal towards cell proliferation or motility and invasiveness. This will indicate whether inhibition of Rho GTPases may be used as an antitumoral or antimetastatic strategy. Given the high incidence of breast cancer among women in developed countries, both the utilization of Rho as markers for tumor progression and early detection, and inhibition of Rho function may provide efficient ways to improve treatment of breast cancer in the future.

\section{MELANOMA}

RhoC is also overexpressed in highly metastatic melanoma cells as determined through DNA array methodology ${ }^{47}$. And as for breast cancer, overexpression of RhoC in these cells leads to a highly invasive phenotype, pointing to a general role of RhoC in promoting metastasis in human tumors. In addition to RhoC, melanoma cells also utilize RhoA and Cdc42 to acquire a metastatic phenotype and to promote cell proliferation ${ }^{48-50}$. Overexpression of the Eph receptor and ephrins in melanomas has been detected, as well as in other human tumors. Eph receptor signaling induces cytoskeletal changes necessary for the invasive capacity of melanoma cells in a RhoA-dependent manner ${ }^{48}$. RhoA mediates cell rounding and membrane blebbing that take place during detachment and migration of the cells, thus directly providing the structural background for proper metastasis. As well, RhoA directly interacts and is activated by GM3 ganglioside, a melanoma-associated antigen ${ }^{50}$. A second melanoma cell surface antigen named melanoma chondroitin sulphate proteoglycan (MCSP) implicated in melanoma cell growth and invasion signals through Cdc42 to promote cell-spreading ${ }^{49}$. Accor- dingly, constitutively active Cdc42 is found in melanoma cells that express MCSP proteoglycan. At last, fusion of the RhoH gene to BCL6 gene in non-Hodgkin's lymphoma (NHL) has been detected in some cases of NHL, although its implication in proliferation has not yet been determined ${ }^{47}$.

\section{COLORECTAL TUMORS}

It has been proposed that a high proportion of colon cancers overexpress RhoA ${ }^{40}$. Furthermore, several aspects of colon tumor biology have been related to Rho GTPases. For instance, proteomic analysis of 15 normal colon specimens and 13 colonic polyps revealed that RhoGDI is underexpressed in the polyps compared to the normal colon tissue ${ }^{51}$. Although, RhoA was not overexpressed in any polyp analyzed, the low expression of RhoGDI implies that RhoA activity might be enhanced in the polyp with respect to the normal tissue. At last, leptin receptor and leptin-induced migration of colonic epithelial cancer cells, such as LoVo, HCT-8/511, and Caco-2, is dependent on RhoA and Rac1, since introduction of dominant negative mutants of these completely abolished invasiveness of the tumoral cells ${ }^{52}$.

\section{LUNG TUMORS}

As with colon cancer, it has been proposed that lung cancers overexpress $\mathrm{RhoA}^{40}$. Again, little recent data is available with larger sample numbers or with respect to the correlation between tumor grade and Rho overexpression. With respect to overexpression, a large percentage of over 50 stage I non-small cell lung carcinomas contained moderate to high overexpression of Rac1 although with no prognostic information. Recently, Varker et al (2003) have further studied the expression pattern of RhoA small cell lung carcinoma and non-small cell lung carcinoma. They have found that expression and activation of RhoA is greater in SCLC cell lines than in NSCLC cell lines ${ }^{53}$. As well, they have observed that inhibition of RhoA in both SCLC cell lines results in cell-cell compaction, adhesion and spreading on collagen IV. On the other hand, inhibition of RhoA in NSCLC cells induces cell spreading. Interestingly, cell proliferation is reduced by Rho inactivation in the majority of the NSCLC cell lines, but not the SCLC cell lines.

Moreover, other works have already pointed a role of RhoA in lung carcinogenesis. For instance, both RhoA and H-Ras repress the expression of nitric oxide synthase-2 (NOS-2) in a lung cancer-derived cell line A549 ${ }^{54}$. NOS-2 activity is related to reduced proliferation, thus Rho would presumably eliminate this antiproliferative signal in lung carcinogenesis. And inhibition of RhoA by C3 exoenzyme or through ADPribosylation leads to an increase in cadherin-based 
adhesion and loss of motility of small-cell lung carcinoma cells ${ }^{54}$. As for other human cancers, the role of Rho GTPases in lung cancer appears to be dichotomous promoting cell proliferation and cell motility or invasion.

\section{OTHER TUMORS}

Other types of human tumors contain alterations in Rho signaling. This is the case of testicular germ cell tumors that display high levels of RhoA, but not RhoB or RhoC ${ }^{5-56}$. The level of RhoA mRNA is greater in tissue obtained from the testis tumor than in normal tissue. Furthermore, mixed tumors with seminoma and nonseminoma contain higher levels of RhoA than tumors with only seminoma, indicating that expression of RhoA correlates with tumor stage and aggressiveness.

Rho GTPases are dysregulated or overexpressed in a number of other human tumors. For instance, migration and in vivo invasiveness of human hepatocellular carcinoma cell lines is dependent on RhoA, since inhibition of RhoA signaling leads to a significant reduction of intrahepatic metastasis produced by hepatocellular carcinoma cell lines injected in nude mi$\mathrm{ce}^{57-58}$. As well, RhoA, Rac2 and Cdc42 are overexpressed in human head and neck squamous cell carcinomas $^{59}$. At last, both mRNA and proteins levels of RhoA are elevated in pelvic/ureteric cancer with an increase in lymph node metastasis and with poor $\operatorname{prognosis}^{60}$.

\section{RHO GTPASES REGULATORS IN HUMAN CANCERS}

Aberrant expression of upstream activators of Rho GTPases has been detected in several human tumors. In this sense, it has been proposed that increased RhoA activity might occur as a consequence of the overexpression of a RhoGEF termed GEF720 in neuroblastomas ${ }^{61}$. Another example for the dysregulation of a RhoGEF in human cancers has been found in renal carcinomas. Although Tiam-1 expression correlates inversely with renal tumoral invasion, an effect predicted for Tiam-1 in invasiveness of epithelial cells, mutations in Tiam-1 have been found in renal carcinomas that result in a constitutively active protein that leads to sustained Rac1 activation ${ }^{62-63}$. Recently, Malliri et al (2002) have generated mice that lack Tiam1 that will enable to study the specific role of Tiam1 signaling in different tumor models. For instance, in a model of skin carcinogenesis it was found that Tiam1 is necessary for tumor initiation and promotion, but opposes tumor progression in a Ras-dependent manner ${ }^{64}$. These results are quite interesting since they indicate that the role of Tiam1 in tumorigenesis is tumor specific.
Other Rho GEFs are implicated in human cancers. For instance, fusion of a RhoGEF to MLL, termed LARG, and mutation of leukemia-associated RhoGEF have been found in acute myeloid leukemias (AML) and leukemias, respectively ${ }^{65-66}$. LARG has been later shown to activate RhoA in vivo suggesting a role of LARG/RhoA in progression of leukemia ${ }^{67}$. In addition, loss of RhoGDI expression in advanced metastatic bladder cancers compared to less aggressive tumors has been detected, suggesting that RhoA might play an important role in the metastatic cascade of bladder carcinoma ${ }^{68}$.

\section{GENETIC ALTERATION IN RHO GTPASES}

Although no point mutations in any member of the Rho family GTPases have been found in any human tumor, two independent works have described the expression of Rac1 splice variants in breast and colon cancers ${ }^{69-70}$. In breast carcinomas a Rac1 isoform, termed Rac1b, with an insertion of 19 codons next to switch II was detected. This mutation promotes fast cycling of both GTP-binding and hydrolysis leading to an overall increase in Rac1 signaling. Furthermore, Rac1b is significantly highly expressed in breast cancer tissues compared to normal breast tissue with high expression in ductal carcinoma-in situ, primary breast cancer and lymph node metastases ${ }^{69}$. With respect to colon cancer, high expression of a Rac1 variant, also termed Rac1b, with a similar insertion of 19 amino acids adjacent to the switch II was detected in colorectal cancers with respect to normal non-tumoral tissue ${ }^{70}$. Expression of Rac1b splice variant was also mostly expressed in skin and epithelial tissues from the intestinal tract, but the expression level was enhanced in the tumoral tissue. The recent cloning and characterization of the structure of the Rac1 gene, with the identification of its promoter region will provide useful to understand the differential expression of Rac1 between tumoral and normal tissue as well as providing clues as to how Rac1 splice variants arise ${ }^{71}$.

\section{CONCLUDING REMARKS}

The specific role of Rho GTPase signaling in all the different human cancers described above is starting to be understood. The information obtained on Rho signaling pathways and effects through conventional and new biochemical techniques with established cell lines may provide essential to delineate the elements of these pathways in each of the tumors described above. The precise role of Rho in every different tumor will need to be determined in order to better predict the tumor progression and to better treat a specific tumor. One important issue to study with concern to Rho expression in different human tumors is the cause and 
nature of such expression. So far no activating mutations have been found within the coding sequence of Rho proteins in human tumors. In addition, although no changes in the levels of Rho GTPases mRNA levels have been detected in colon and breast tumor compared to normal tissue, this is not the case for testicular germ tumors where an increase in Rho mRNA level is observed. Therefore, to date it seems that Rho overexpression in human tumors is not a genetic event, but it rather depends on other genetic instabilities or tumor environment. The characterization of these elements that govern Rho dysregulation will provide useful information to better understand the role of Rho in different stages of tumor. As well, it will set the ground for a better target-based anticancer treatment. Many works are already available that have dissected some of these pathways downstream of Rho GTPases that contribute to the proliferative and the metastatic signals. As well, recent findings in Rho-mediated transcriptional regulation with respect to tumorigenesis have been made that further strengthen the idea that many signal transduction pathways are regulated by Rho GTPases that contribute to the overall biologic outcome.

\section{ACKNOWLEDGMENTS}

This work was supported by Grants SAF2001-2042 and SAF2002-02437 from Department of Science and Technology (MCYT).

\section{References}

1. Van Aelst L, D’Souza-Schorey C. Rho GTPases and signaling network. Genes \& Dev 1997;11:2295-322.

2. Aznar S, Lacal JC. Searching new targets for anticancer drug design: the families of Ras and RhoGTPases and their effectors. Prog Nucleic Acid Res Mol Biol 2001;67: 193-234.

3. Aznar S, Lacal JC. Rho signals to cell growth and apoptosis. Cancer Lett 2001;165:1-10.

4. Bar-Sagi D, Hall A. Ras and Rho GTPases: a family reunion. Cell 2000;103:227-38.

5. Ridley AJ. Rho family proteins: coordinating cell responses. Trends in cell Biol 2001;11:471-7.

6. Schmitz AAP, Govek E-E, Bottner B, Van Aelst L. Rho GTPases: Signaling, Migration and Invasion. Exp Cell Research 2000;261:1-12.

7. Settleman J.Rac ' $\mathrm{n}$ Rho: the music that shapes a developing embryo. Dev Cell 2001;1:321-31.

8. Settleman J.Getting in shape with Rho.Nat Cell Biol 2000;2:E7-9.

9. Boettner B, Van Aelst L.The role of Rho GTPases in disease development. Gene 2002;286:155-74.

10. Tao W, Pennica D, Xu L, Kalejta RF, Levine AJ. Wrch-1, a novel member of the Rho gene family that is regulated by Wnt-1. Genes Dev 2001;5:1796-807.

11. Ballestero RP, Esteve P, Perona P, Jiménez B, Lacal JC. Biological function of Aplysia californica rho gene. The Superfamily of ras related Genes. NATO Advanced Science Institute Series, 1991;vol. A220:273-42. Plenum Press.
12. Perona R, Esteve P, Jiménez P, et al. Tumorigenic activity of rho genes from Aplysia californica. Oncogene 1993;8:1285-92.

13. Michiels F, Habets GG, Stam JC, van der Kammen RA, Collard JG. A role for Rac in Tiam1-induced membrane ruffling and invasion. Nature 1995;375:338-40.

14. del Peso L, Hernández-Alcoceba R, Embade N, et al. Rho proteins induce metastatic properties in vivo. Oncogene 1997; 15: 3047-3057.

15. Hernández-Alcoceba R, del Peso L, Lacal JC. Ras family of GTPases in cancer cell invasion. Cellular and Molecular Life Sciences 2000;57:65-76.

16. Yoshioka K, Matsumura F, Akedo H, Itoh K. Small GTPbinding protein Rho stimulates the actomyosin system, leading to invasion of tumor cells. J Biol Chem 1998; 273:5146-54.

17. Pruitt K, Der CJ. Ras and Rho regulation of the cell cycle and oncogenesis. Cancer Lett 2001;171:1-10.

18. McCormick F. Signal transduction. Why Ras needs Rho. Nature 1998;394:220-1.

19. Khosravi-Far R, Campbell S, Rossman KL, Der CJ. Increasing complexity of Ras signal transduction: involvement of Rho family proteins. Adv Cancer Res 1998; 72:57-107.

20. Qiu RG, Chen J, McCormick F, Symons M. A role for Rho in Ras transformation. Proc Natl Acad Sci USA 1995;92:11781-5.

21. Qiu RG, Chen J, Kirn D, McCormick F, Symons M. An essential role for Rac in Ras transformation. Nature 1995;37: 457-9.

22. Qiu RG, Abo A, McCormick F, Symons M. Cdc42 regulates anchorage-independent growth and is necessary for Ras transformation. Mol Cell Biol 1997;17:34449-58.

23. Nur-E-Kamal MS, Kamal JM, Qureshi MM, Maruta H. The CDC42-specific inhibitor derived from ACK-1 blocks v-Ha-Ras-induced transformation. Oncogene 1999;18:7787-93.

24. Boerner JL, Danielsen AJ, McManus MJ, Maihle NJ. Activation of Rho is Required For Ligand-independent Oncogenic signaling by a mutant EGF Receptor. J Biol Chem 2000;10:3691-5.

25. Kim BC, Yi JY, Yi SJ, et al. Rac GTPase activity is essential for EGF-induced mitogenesis. Mol Cell 1998;8:90-5.

26. Sachdev P, Jiang XY, Li W, Miki T, Nur-E-Kamal MS, Wang LH. Differential requirement for Rho family GTPases in an oncogenic insulin-like growth factor-I receptor-induced cell transformation. J Biol Chem 2001; 276:26461-71.

27. Barone MW, Sepe L, Melillo RM, et al. RET/PTC1 oncogene signaling in PC C134 thyroid cells requires the small GTP-binding protein Rho. Oncogene 2001;20:6973-82.

28. Royal I, Lamarche-Vane N, Lamorte L, Kaibuchi K, Park M. Activation of Cdc42, rac, PAK, and rho-kinase in response to hepatocyte growth factor differentially regulates epithelial cell colony spreading and issociation. Mol Biol Cell 2000;11:1709-25.

29. Kamei T, Matozaki T, Sakisaka T, et al. Coendocytosis of cadherin and c-Met to disruption of cell-cell adhesion in MDCK cells: regulation by Rho, Rac and Rab small G proteins. Oncogene 1999; 18: 6776-84.

30. Whitehead IP, Zohn IE, Der CJ. Rho GTPase-dependent transformation by $\mathrm{G}$ protein-coupled receptors. Oncogene 2001;20:1547-55.

31. Nakamoto M, Teramoto H, Matsumoto S, Igishi T, Shimizu E. K-ras and rhoA mutations in malignant pelural effusion. Int J Oncol 2001;19:971-6.

32. Suwa H, Ohshio G, Imamura T, et al. Overexpression of the rhoC gene correlates with progression of ductal adenocarcinoma of the pancreas. Br J Cancer 1998;177:147-52. 
33. Rihet S, Vielh P, Camonis J, Goud B, Chevillard S, de Gunzburg J.Mutation status of genes encoding RhoA, Rac1, and Cdc42 GTPases in a panel of invasive human colorectal and breast tumors.J Cancer Res Clin Oncol 2001;127:733-8.

34. Suwa H, Ohshio G, Imamura T, et al. Overexpression of the rhoC gene correlates with progression of ductal adenocarcinoma of the pancreas. Br J Cancer 1998;177:14752.

35. Kusama T, Mukai M, Iwasaki T, et al. 3-hydroxy-3methylglutaryl-coenzyme a reductase inhibitors reduce human pancreatic cancer cell invasion and metastasis. Gastroenterology 2002;122:308-17.

36. Kusama T, Mukai M, Iwasaki T, et al. Inhibition of epidermal growth factor-induced RhoA translocation and invasion of human pancreatic cancer cells by 3-hydroxy-3-methylglutaryl-coenzyme a reductase inhibitors. Cancer Res 2001;61:4885-91.

37. Van Golen KL, Davies S, Wu ZF, et al. A novel putative low-affinity insulin-like growth factor-binding protein, LIBC (lost ininflammatory breast cancer), and RhoC GTPase correlate with the inflammatory breast cancer phenotype. Clin Cancer Res 1999;5:2511-9.

38. Van Golen KL, Wu ZF, Qiao XT, Bao L, Merajver SD. RhoC GTPase, a novel transforming oncogene for human mammary epithelial cells that partially recapitulates the inflammatory breast cancer phenotype. Cancer Res 2000;60:5832-8.

39. Van Golen KL, Wu ZF, Qiao XT, Bao L, Merajver SD. RhoC GTPase overexpression modulates induction of angiogenic factors in breast cells. Neoplasia 2000;2:41825.

40. Fritz G, Just I, Kaina B. Rho GTPases are over-expressed in human tumors. Int J Cancer 1999;81:682-7.

41. Fritz G, Brachetti C, Bahlmann F, Schmidt M, Kaina B. Rho GTPases in human breast tumours: expression and mutation analyses and correlation with clinical parameters. Br J Cancer 2002;87:635-44.

42. Bouzahzah B, Albanese C, Ahmed F, et al. Rho family GTPases regulate mammary epithelium cell growth and metastasis through distinguishable pathways. Mol Med 2001;7:816-30.

43. Denoyelle C, Vasse M, Korner M, et al. Cerivastatin, an inhibitor of HMG-CoA reductase, inhibits the signaling pathways involved in the invasiveness and metastatic properties of highly invasive breast cancer celllines: an in vitro study. Carcinogenesis 2001;22:1139-48.

44. Bourguignon LY. CD44-mediated oncogenic signaling and cytoskeleton activation during mammary tumor progression. J Mammary Gland Biol Neoplasia 2001; 6:287-97

45. Bourguignon LY, Zhu H, Shao L, Zhu D, Chen YW. Rhokinase (ROK) promotes CD44v (3,8-10)-ankyrin interaction and tumor cell migration in metastatic breast cancer cells. Cell Motil Cytoskeleton 1999;43:269-87.

46. Clark EA, Golub TR, Lander ES, Hynes RO. Genomic analysis of metastasis reveals an essential role for RhoC. Nature 2000;406: 532-5.

47. Preudhomme C, Roumier C, Hildebrand MO, et al. Nonrandom 4p13 rearrangements of the RhoH/TTF gene, enconding a GTP-binding protein, in non-Hodgkin's lymphoma and multiple myeloma. Oncogene 2000;19: 2023-32.

48. Lawrenson ID, Wimmer-Kleikamp SH, Lock P, et al. Ephrin-A5 induces rounding, blebbing and de-adhesion of EphA3-expressing 293T and melanoma cells by CrkII and Rho-mediated signalling. J Cell Sci 2002;115:1059-72.

49. Eisenmann KM, McCarthy JB, Simpson MA, et al. Melanoma chondroitin sulphate proteoglycan regulates cell spreading through Cdc42, Ack-1 and p130cas. Nat Cell Biol 1999;1:507-13.

50. Yamamura S, Handa K, Hakomori S. A close association of GM3 with c-Src and Rho in GM3-enriched microdomains at the B16 melanoma cell surface membrane: a preliminary note. Biochem Biophys Res Commun 1997; 236:218-22.

51. Melis R, White R. Characterization of colonic polyps by two-dimensional gel electrophoresis. Electrophoresis 1999;20:1055-64.

52. Attoub S, Noe V, Pirola L, et al. Leptin promotes invasiveness of kidney and colonic epithelial cells via phosphoinositide3-kinase-, rho-, and rac-dependent signaling pathways Faseb J 2000;14:2329-38.

53. Varker KA, Phelps SH, King MM, Williams CL. The small GTPase RhoA has greater expression in small cell lung carcinoma than in non-small cell lung carcinoma and contributes to their unique morphologies. Int J Oncol 2003;22:671-81.

54. Delarue FL, Taylor BS, Sebti SM. Ras and RhoA suppress whereas RhoB enhances cytokine-induced transcription of nitric oxide synthase- 2 in human normal liver AKN-1 cells and lung cancer A-549 cells. Oncogene 2001;20:6531-7.

55. Kamai T, Arai K, Tsujii T, Honda M, Yoshida K. Overexpression of RhoA mRNA is associated with advanced stage in testicullar germ cell tumour. BJU Int 2001;87: 227-231.

56. Kamai T, Arai K, Sumi S, et al. The rho/rho-knase pathway is involved in the progression of testicular germ cell tumor. BJU Int 2002;89:449-53.

57. Takamura M, Sakamoto M, Genda T, Ichida T, Asakura $\mathrm{H}$, Hirohashi S. Inhibition of intrahepatic metastasis of human hepatocellular carcinoma by Rho-associated protein kinase inhibitor Y-27632. Hepatology 2001;33: 577-81.

58. Genda T, Sakamoto M, Ichida T, et al. Cell motility mediated by Rho and Rho-associated protein kinase plays a critical role in intrahepatic metastasis of human hepatocellular carcinoma. Hepatology 1999;30:1027-36.

59. Abraham MT, Kuriakose MA, Sacks PG, et al. Motilityrelated proteins as markers for head and neck squamous cell cancer Laryngoscope 2001;111:1285-9.

60. Kamai T, Kawakami S, Koga F, et al. RhoA is associated with invasion and lymph node metastasis in upper urinary tract cancer. BJU Int 2003;91:234-8.

61. De Toledo M, Coulon V, Schmidt S, Fort P, Blangy A. The gene for a new brain specific RhoA exchange factor maps to the highly unstable chromosomal region 1p36.2-1p36.3. Oncogene 2001;20:7307-17.

62. Hordijk PL, Ten Klooster JP, van der Kammen RA, Michiels F, Oomen LC, Collard JG. Inhibition of invasion of epithelial cells by Tiam1-Rac signaling. Science 1997; 278:1464-6.

63. Engers R, Zwaka TP, Gohr L, Weber A, Gerharz CD, Gabbert HE. Tiam1 mutations in human renal-cell carcinomas. Int J Cancer 2000;88:369-76.

64. Malliri A, van der Kammen RA, Clark K, van der Valk M, Michiels F, Collard JG.Mice deficient in the Rac activator Tiam1 are resistant to Ras-induced skin tumours.Nature 2002;417:867-71.

65. Reuther GW, Lambert QT, Booden MA, et al. Leukemiaassociated Rho guanine nucleotide exchange factor, a Dbl family protein found mutated in leukemia, causes transformation by activation of RhoA. J Biol Chem 2001; 276:27145-51.

66. Kourlas PJ, Strout MP, Becknell B, et al. Identification of a gene at 11 q23 encoding a guanine nucleotide exchange factor: evidence for its fusion with MLL in acute 
myeloid leukemia. Proc Natl Acad Sci USA 2000;97: 2145-50.

67. Fukuhara S, Chikumi H, Gutkind JS Leukemia-associated Rho guanine nucleotide exchange factor (LARG) links heterotrimeric $G$ proteins of the $G(12)$ family to Rho. FEBS Lett 2000;485:183-8.

68. Seraj MJ, Harding MA, Gildea JJ, Welch DR, Theodorescu D The relationship of BRMS1 and RhoGDI2 gene expression to metastatic potential in lineage related human bladder cancer cell lines. Clin Exp Metastasis 2000; 18:519-25.
69. Jordan P, Brazao R, Boavida MG, Gespach C, Chastre E. Cloning of a novel human Rac1b splice variant with increased expression in colorectal tumors. Oncogene 1999;18:6835-9.

70. Schnelzer A, Prechtel D, Knaus U, et al. Rac1 in human breast cancer: overexpression, mutation analysis, and characterization of a new isoform, Rac1b. Oncogene 2000;19:3013-20.

71. Matos P, Skaug J, Marques B, et al. Small GTPase Rac1: structure, localization, and expression of the human gene. Biochem Biophys Res Commun 2000;277:741-51. 